\title{
Curcumin inhibits hypoxia inducible factor-1 $\alpha$-induced epithelial-mesenchymal transition in HepG2 hepatocellular carcinoma cells
}

\author{
WANXING DUAN $^{1 *}$, YUANHONG CHANG $^{2 *}$, RONG LI $^{1}$, QINHONG XU $^{1}$, JIANJUN LEI $^{1}$, \\ CAIQIAO YIN ${ }^{2}$, TING $\mathrm{LI}^{2}$, YANZHAO WU ${ }^{2}$, QINGYONG MA ${ }^{1}$ and XUQI $\mathrm{LI}^{3}$ \\ ${ }^{1}$ Department of Hepatobiliary Surgery, First Affiliated Hospital of Medical College, Xi'an Jiaotong University, \\ Xi'an, Shaanxi 710061; ${ }^{2}$ Department of Gastroenterology, Xi'an No. 4 Hospital, Affiliated Guangren Hospital, \\ School of Medicine, Xi'an Jiaotong University, Xi'an, Shaanxi 710004; ${ }^{3}$ Department of General Surgery, \\ First Affiliated Hospital of Medical College, Xi'an Jiaotong University, Xi'an, Shaanxi 710061, P.R. China
}

Received December 12, 2013; Accepted July 1, 2014

DOI: $10.3892 / \mathrm{mmr} .2014 .2551$

\begin{abstract}
Hepatocellular carcinoma (HCC) accounts for the majority of liver cancers. A hypoxic microenvironment is a common feature of HCC, and is associated with malignant invasion, metastasis and epithelial-mesenchymal transition (EMT) changes. Curcumin is a botanical agent derived from the dried rhizome of Curcuma longa. Although a number of preclinical studies have shown that curcumin has anticancer properties when administered in a normoxic microenvironment, no studies have directly examined the effect of curcumin on preventing HCC invasion and metastasis under hypoxic conditions. This study aimed to determine whether curcumin has effects on the hypoxia-induced malignant biological behavior of $\mathrm{HCC}$. $\mathrm{CoCl}_{2}$ was used to establish a hypoxia model in vitro. The results showed that curcumin significantly decreased hypoxia-induced hypoxia inducible factor- $1 \alpha$ (HIF-1 $\alpha$ ) protein level in HepG2 cells. Furthermore, cell proliferation, migration and invasiveness, as well as EMT changes associated with HIF-1 $\alpha$ accumulation generated by a hypoxic microenvironment, were eliminated by curcumin. In conclusion, these data indicate that curcumin may be a viable anticancer agent in the treatment of HCC.
\end{abstract}

Correspondence to: Professor Xuqi Li, Department of General Surgery, First Affiliated Hospital of Medical College, Xi'an Jiaotong University, 277 West Yanta Road, Xi'an, Shaanxi 710061, P.R. China E-mail: lixuqi@163.com

*Contributed equally

Key words: hepatocellular carcinoma, hypoxia, hypoxia inducible factor-1 $\alpha$, epithelial-mesenchymal transition, curcumin

\section{Introduction}

Hepatocellular carcinoma (HCC) is the most common type of liver malignancy (1). Although the incidence of certain types of cancer have been declining, that of HCC has been increasing worldwide $(2,3)$. In the United States between 1975 and 2005, the 5 -year survival rate is $<2 \%$ in patients with advanced stages of the disease (2). Radical surgery remains the most effective strategy to treat HCC. However, $\sim 70 \%$ of patients relapse or develop metastases within 5 years of undergoing this treatment (2). Therefore, more effective interventions for targeting cancer metastasis are required in order to reduce the morbidity and mortality rates associated with HCC.

The initiation of cancer metastasis requires migration and invasion of cells, which is enabled by epithelial-mesenchymal transition (EMT) (4). EMT is a biological process in which epithelial cancer cells in primary tumors lose their cell polarity and cell-cell adhesion, and gain increased migratory and invasive properties in order to become mesenchymal cells. The loss of E-cadherin, the key marker of epithelial cells, is hypothesized to be a crucial event in the initiation of EMT (5). Downregulation of E-cadherin is mediated by overexpression of several EMT-inducing factors, such as snail $(6,7)$. The gain of mesenchymal markers (e.g., vimentin and $\mathrm{N}$-cadherin) is another feature of EMT. Accumulating data have demonstrated a correlation between EMT, and the progression and metastasis of HCC $(8,9)$.

Hypoxia is a common characteristic of solid tumor microenvironments, and is caused by aberrant neovascularization of the rapidly growing tumor mass (10). Evidence indicates that this hypoxic microenvironment can facilitate tumor metastasis (11). The transcription factor hypoxia-inducible factor- $1 \alpha$ (HIF-1 $\alpha$ ), a key mediator of the cellular response to hypoxia, is overexpressed in a wide variety of solid tumors, including HCC (12). HIF-1 $\alpha$ consists of an oxygen-dependent degradation domain (ODDD) that mediates oxygen-regulated stability (13). In normoxic conditions, hydroxylation of two proline residues and acetylation of a lysine residue at the ODDD of HIF-1 $\alpha$ leads to HIF-1 $\alpha$ degradation by the ubiquitin-proteasome 
pathway. In hypoxia, the HIF-1 $\alpha$ subunit remains stable, accumulates and translocates to the nucleus, where it regulates the expression of target genes. These genes in turn, regulate a variety of cellular processes, such as angiogenesis (14) and EMT (15). Recent evidence suggests that stabilization of the HIF-1 $\alpha$ transcription complex, caused by intratumor hypoxia, promotes tumor progression and metastasis (11).

Curcumin is a biological product obtained from the ground rhizomes of Curcuma longa, which is a member of the zingiberaceae plant family, and is widely cultivated in Southeast Asian countries (16). Previous studies have demonstrated medicinal qualities, including antiseptic (17), anti-oxidative (18), anti-inflammatory (19), anticoagulative (20) and anti-atherosclerotic (21) properties. Moreover, curcumin has been shown to suppress the transformation, proliferation and metastasis of several types of cancer cells in vivo and in vitro (22). There is extensive literature suggesting that the potential anticancer effects of curcumin may, in part, be mediated through its regulation of various transcription factors, for example nuclear factor $(\mathrm{NF})-\kappa \mathrm{B}$ and signal transducers and activators of transcription (23-25). However, previous studies have focused on the effects of curcumin under normoxic conditions. The aim of this study was to determine whether curcumin can inhibit the HIF- $1 \alpha$-associated proliferation, migration, invasion and EMT in HCC in a hypoxic microenvironment, which may more realistically model tumor conditions.

\section{Materials and methods}

Cell culture and cell treatments. Cells from the human hepatoma cell line, HepG2 (American Type Culture Collection, Rockville, MD, USA), were cultured in Dulbecco's modified Eagle's medium (DMEM; HyClone, South Logan, UT, USA) containing $10 \%$ fetal bovine serum (FBS; HyClone). Cells were grown in a $5 \% \mathrm{CO}_{2}$ atmosphere at $37^{\circ} \mathrm{C}$. To establish hypoxic conditions, the culture medium was supplemented with $10 \mathrm{~mol} / \mathrm{l}$ $\mathrm{CoCl}_{2}$ dissolved in $\mathrm{ddH}_{2} \mathrm{O}$ (26). Curcumin was dissolved in dimethyl sulfoxide (DMSO; Sigma, St. Louis, MO, USA). The concentration of curcumin (Wako, Tokyo, Japan) in the medium of the HepG2 cells was $10 \mu \mathrm{mol} / \mathrm{l}$. The cells in the control group were treated with DMSO only, under identical conditions.

MTT proliferation assays. To determine the cell proliferation rate, 5,000 cells/well were plated in 96-well plates, cultured for $12 \mathrm{~h}$ and then treated with $\mathrm{CoCl}_{2}$ and curcumin. Cells treated with DMSO served as a control. At indicated time points (24, 48, 72 and $96 \mathrm{~h}), 20 \mu \mathrm{l}$ of $5 \mathrm{mg} / \mathrm{ml} \mathrm{3-(4,5-dimethylthi-}$ azol-2-yl)-2,5-diphenyltetrazolium bromide (MTT; Sigma) was added to each well and cells were incubated for an additional $4 \mathrm{~h}$ at $37^{\circ} \mathrm{C}$ (27). Following MTT incubation, $150 \mu \mathrm{l}$ DMSO (Sigma) per well was added to dissolve the crystals. Viable cells were counted by measuring absorbance at $490 \mathrm{~nm}$ using a spectrophotometer (Bio-Rad, Hercules, CA, USA).

Cell scratch-wound assays. For cell migration assessment, $5 \times 10^{5}$ cells/well were seeded in 6-well plates and starved for $24 \mathrm{~h}$ immediately after cells had reached full confluency. Cells were scratched with a $200 \mathrm{ml}$ pipette tip. Non-adherent cells were removed with phosphate-buffered saline (PBS), and baseline cell layers were photographed $(0 \mathrm{~h}$ point; Nikon TE300,
Tokyo, Japan) and placed into the growth medium. After $24 \mathrm{~h}$, matched-pair wound regions were photographed. The cell migration distance was calculated as the initial scratch width ( $0 \mathrm{~h}$ point) plus the wound healing width ( $24 \mathrm{~h}$ point) $(27)$.

In vitro invasion assay. Matrigel invasion assays were performed with 24-well transwell inserts ( $8 \mu \mathrm{m}$; Millipore co., Billerica, MA, USA) as described previously (28). Briefly, the lower surface of the membrane was coated with Matrigel ${ }^{\mathrm{TM}}$ (BD Biosciences, Franklin Lakes, NJ, USA). HepG2 cells were pre-treated in a 6-well plate for $24 \mathrm{~h}$ and then suspended in the upper chamber in a serum-free medium. Lower compartments were filled with DMEM containing 10\% FBS. After 48 h, non-invading cells were gently removed by scraping with a cotton swab, and invading cells in the lower side of the membrane were fixed with $4 \%$ paraformaldehyde and stained with crystal violet. The average number of invasive cells in 10 random fields selected on each membrane was calculated using a microscope (x20; Nikon Eclipse TE2000-U; Nikon Instruments, Inc., Melville, NY, USA) in order to quantify the extent of invasion. Each set of experiments was performed in triplicate (29).

RNA extraction and quantitative polymerase chain reaction $(q P C R)$. Total RNA was extracted from monolayers of cultured HepG2 cells with TRIzol reagent (Invitrogen, Carlsbad, CA, USA). cDNA was synthesized from $5 \mu \mathrm{g}$ RNA using Takara Reverse Transcription Reagent (Takara, Tokyo, Japan) according to the manufacturer's instructions. The primer sequences were: Forward: 5'-CAAAACACACAGCGAAGC-3' and reverse: 5'-TCAACCCAGACATATCCACC-3' for HIF-1 $\alpha$; forward: 5'-CATCACTATCGGCAATGAGC-3' and reverse: 5'-GACAGCACTGTGTTGGCATA-3' for $\beta$-actin; forward: 5'-ATTCTGATTCTGCTGCTCTTG-3' and reverse: 5'-AGTCCTGGTCCTCTTCTCC-3' for E-cadherin; forward: 5'-CTTCTCCTCTACTTCAGTCTC TTC-3' and reverse: 5'-CGTGTG GCTTCGGATGTG-3' for snail and forward: 5'-AATGACCGCTTCGCCAAC-3' and reverse: 5'-CCGCATCTCCTCCTCGTAG-3' for vimentin.

The following cycling conditions were used: $94^{\circ} \mathrm{C}$ for $5 \mathrm{sec}$, $60^{\circ} \mathrm{C}$ for $30 \mathrm{sec}$ and then $72^{\circ} \mathrm{C}$ for $30 \mathrm{sec}$. HIF- $1 \alpha$ and $\beta$-actin were amplified for 35 cycles. HIF- $1 \alpha$ relative expression was analyzed by the comparative $\mathrm{C}_{\mathrm{T}}$ method with $\beta$-actin as the normalization control (30).

Western blotting. Western blot analyses were performed as described previously (28). Briefly, total protein was extracted using Mammalian Protein Lysis Buffer (Thermo Scientific Waltham, MA, USA) after each group of cells was treated for $72 \mathrm{~h}$. Equal quantities of protein were added, separated by SDS-polyacrylamide gel electrophoresis and electro-transferred onto polyvinylidene fluoride membranes (Millipore, Billerica, MA, USA). After blocking the membranes with non-fat milk in PBS with Tween-20 (PBST) for $1 \mathrm{~h}$ at room temperature, the membranes were incubated with specific primary antibodies overnight at $4^{\circ} \mathrm{C}$, and then washed in PBST. The blots were incubated with horseradish peroxidase conjugated-anti-rabbit or anti-mouse monoclonal IgG secondary antibodies (Sigma) at a dilution of 1:10,000 for $1 \mathrm{~h}$. Secondary antibodies were detected by an enhanced chemiluminescence method (Amersham, Piscataway, NJ, USA). The density of specific protein bands 
A

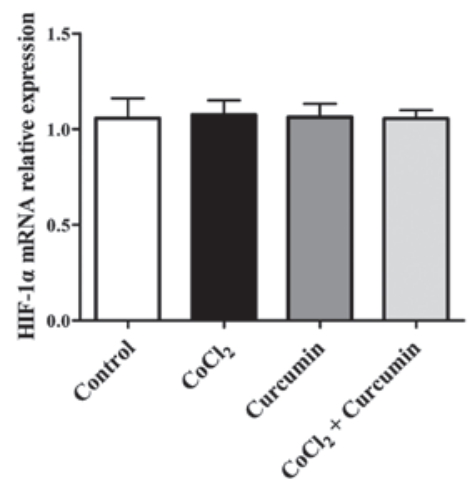

B

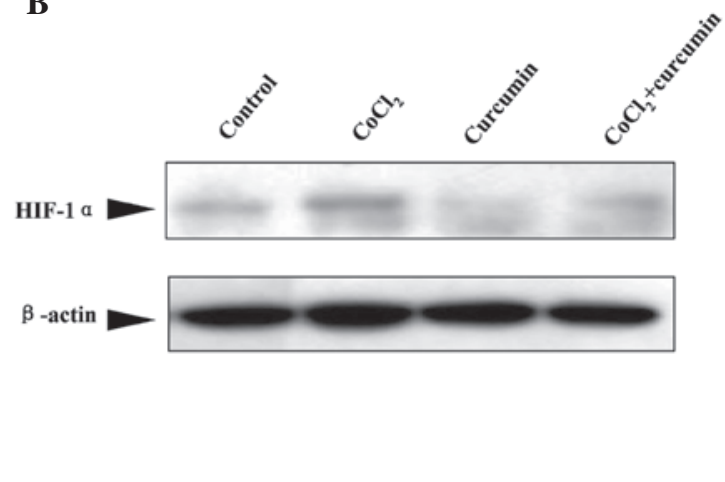

Figure 1. Effect of curcumin on $\mathrm{CoCl}_{2}$-induced HIF-1 $\alpha$ expression. (A) Effects of curcumin (10 $\left.\mu \mathrm{mol} / \mathrm{l}\right)$ and/or $\mathrm{CoCl}_{2}(10 \mu \mathrm{mol} / \mathrm{l})$ on mRNA levels of HIF-1 $\alpha$. The mRNA expression of HIF-1 $\alpha$ was estimated by qPCR in three groups with $\beta$-actin as a normalization control. (B) Immunoblotting results of HIF-1 $\alpha$ expression induced by $\mathrm{CoCl}_{2}$ in $\mathrm{HepG} 2$ cells after curcumin treatment. Blots were normalized to $\beta$-actin protein in each lane. Data represent the results of three independent experiments. Column, mean; bar, standard deviation. HIF-1 $\alpha$, hypoxic inducible factor- $1 \alpha$; qPCR, quantitative polymerase chain reaction.

were determined by Image-Pro Plus 5.0 software (Media Cybernetics, Inc., Rockville, MD, USA). The E-cadherin antibody was purchased from BD Bio-sciences (San Jose, CA, USA) and mouse monoclonal HIF-1 $\alpha$ antibody was purchased from Cell Signaling Technology, Inc. (Beverly, MA, USA). The mouse monoclonal $\beta$-actin, rabbit monoclonal snail and rabbit polyclonal vimentin antibodies were obtained from Santa Cruz Biotechnology, Inc. (Santa Cruz, CA, USA).

Statistical analysis. All experiments were repeated at least three times. Results are expressed as the mean \pm standard deviation. Differences were evaluated using one-way analysis of variance with the least significant difference post hoc test for multiple comparisons via SPSS (version 15.0; SPSS, Chicago, IL, USA). $\mathrm{P}<0.05$ was considered to indicate a statistically significant difference.

\section{Results}

Curcumin inhibits $\mathrm{CoCl}_{2}$-induced HIF-la protein expression. To determine the effect of curcumin on hypoxia-induced HIF-1 $\alpha$ expression, HepG2 cells were treated with $\mathrm{CoCl}_{2}$ and curcumin, separately and in combination. The HIF-1 $\alpha$ expression was measured by qPCR and western blot analysis. As shown in Fig. 1A, no significant changes were found in the expression of HIF-1 $\alpha$ mRNA in HepG2 cells treated with $\mathrm{CoCl}_{2}$ and curcumin, alone or in combination, as compared with the DMSO control group. However, treatment with $\mathrm{CoCl}_{2}$ markedly increased HIF-1 $\alpha$ protein levels (Fig. 1B). HIF-1 $\alpha$ protein levels were reduced by $70 \%$ with curcumin treatment alone compared with the control group. Moreover, accumulation of the HIF-1 $\alpha$ protein induced by $\mathrm{CoCl}_{2}$ was prevented by administration of curcumin. These results confirmed that $\mathrm{CoCl}_{2}$ is an effective inducer of HIF-1 $\alpha$ at the posttranscriptional level. In addition curcumin appeared to inhibit the HIF-1 $\alpha$ protein accumulation induced by $\mathrm{CoCl}_{2}$ without affecting transcription.

Curcumin inhibits HepG2 cell proliferation. A previous study demonstrated that $\mathrm{CoCl}_{2}$-induced HIF-1 $\alpha$ expression was correlated with enhanced cell proliferation (31). To explore the role of curcumin on proliferation, HepG2 cells were seeded

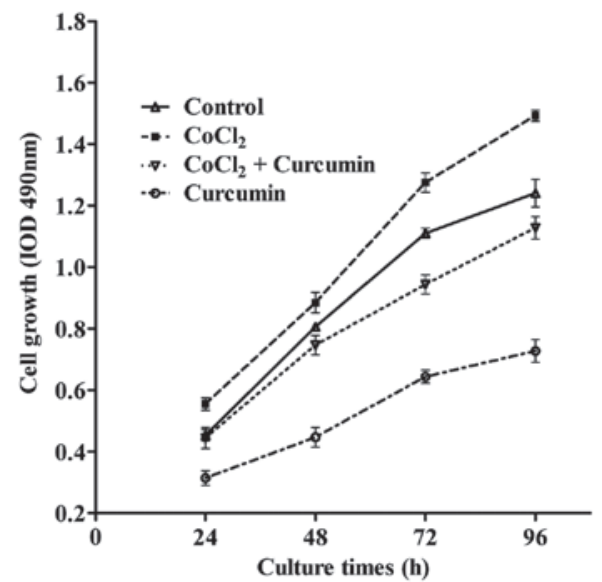

Figure 2. Effects of curcumin on $\mathrm{CoCl}_{2}$-induced proliferation. HepG2 cells were seeded in a 96-well plate followed by $\mathrm{CoCl}_{2}(10 \mu \mathrm{mol} / 1)$ and/or curcumin $(10 \mu \mathrm{mol} / 1)$ administration. At the indicated time points, proliferation rates were measured by the 3-(4,5-dimethylthiazol-2-yl)-2,4-dephenyltetrazolium bromide assay. Data represent the results of three independent experiments. Column, mean; bar, standard deviation. ${ }^{*} \mathrm{P}<0.05$ compared with the control group.

onto 96-well plates, and treated with $\mathrm{CoCl}_{2}$ and curcumin alone or in combination. At the time points indicated in Fig. 2, the proliferative rate of HepG2 cells in each group was determined by the MTT assay. The results demonstrated that the proliferation of HepG2 cells increased in response to the administration of $\mathrm{CoCl}_{2}$ compared with the DMSO control group $(\mathrm{P}<0.05)$. By contrast, curcumin treatment decreased the rate of cell proliferation in a dose-dependent manner. Furthermore, the increased rate of cell proliferation induced by $\mathrm{CoCl}_{2}$ was reduced by $\sim 30 \%$ in the presence of curcumin at each time point measured.

Curcumin inhibits the migration and invasion of HepG2 cells associated with HIF-1 $\alpha$ accumulation. The effect of curcumin on $\mathrm{HCC}$ cell motility after $\mathrm{CoCl}_{2}$ treatment was determined using a wound-healing assay. As shown in Fig. 3A and B, compared with normal controls, HepG2 cells treated with $\mathrm{CoCl}_{2}$ alone exhibited increased migration into the wound area $24 \mathrm{~h}$ after wounding occurred. The migration distance 
A

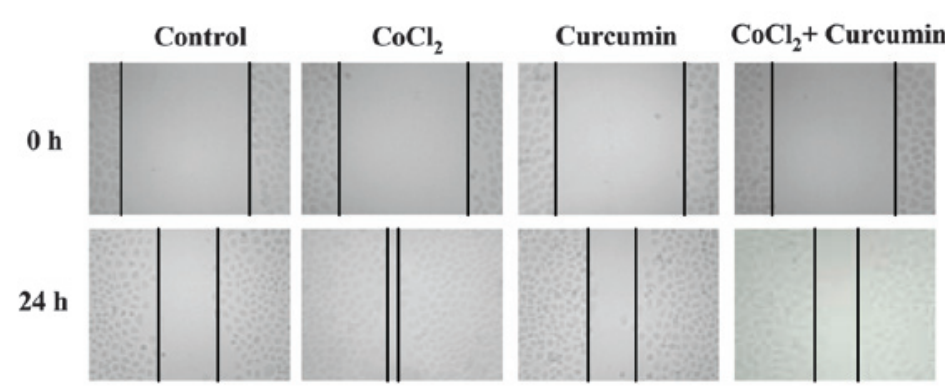

B

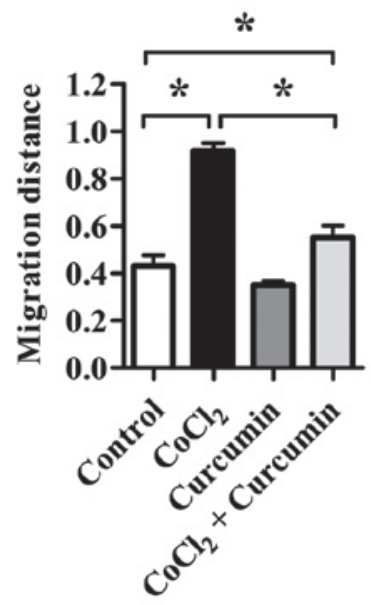

D

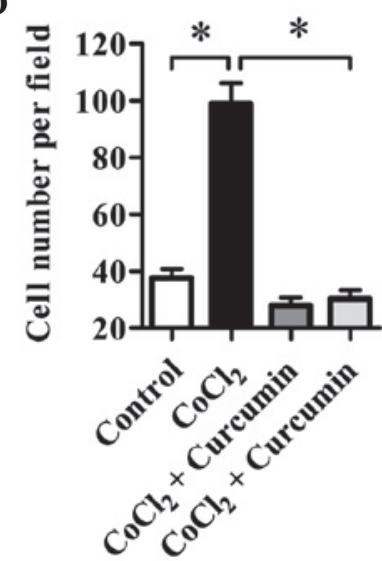

Figure 3. Effects of curcumin on $\mathrm{CoCl}_{2}$-mediated cell migration and invasion. (A) HepG2 cells were grown into monolayers in triplicate in 6-well plates, confluent cultures were starved for $24 \mathrm{~h}$ and scratch assays were perform as described in the Materials and methods section. Curcumin effects on CoCl${ }_{2}$-enhanced motility of HepG2 cells. (B) Cell migration ability was measured by the migration index, which was equal to the initial scratch width (0 h point) plus the wound healing width ( $24 \mathrm{~h}$ point) divided by the initial scratch width. (C) The effects of curcumin on cell invasion after treatment with CoCl ${ }_{2}$. HepG2 cells were seeded into a matrigel-coated invasion chamber and exposed to $\mathrm{CoCl}_{2}$ and/or curcumin for $48 \mathrm{~h}$. The invaded cells in the lower side of the membrand were then stained using crystal violet. (D) The number of migrated cells was quantified by counting the cells from 10 random fields at x 200 magnification. ${ }^{*} \mathrm{P}<0.05$. Column, mean; bar, standard deviation.

A

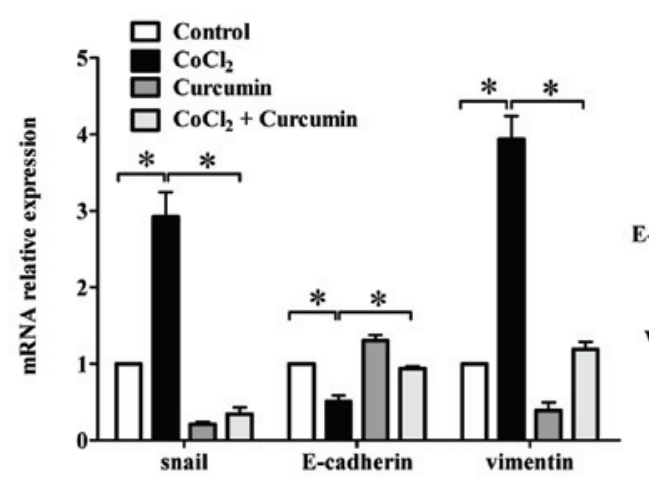

B

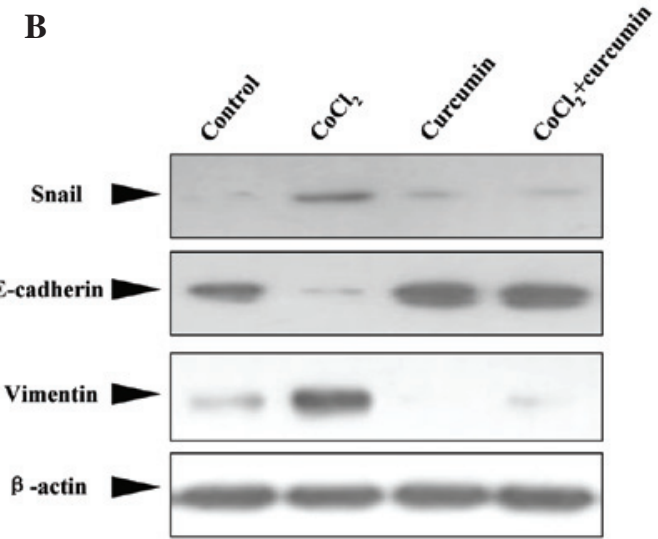

Figure 4. Effects of curcumin on $\mathrm{CoCl}_{2}$-induced changes in EMT-related markers. (A) mRNA Levels of EMT-related markers (snail, E-cadherin and vimentin) as measured by qPCR. The expression of each target gene was quantified using $\beta$-actin as a normalization control. (B) The protein levels of EMT-related markers were measured by western blotting. Protein levels of E-cadherin, vimentin and snail after $\mathrm{CoCl}_{2}$ and curcumin treatment. $\beta$-actin was used as the normalization control. "P $<0.05$. Results are presentedas the mean $\pm \mathrm{SD}$ of three independent experiments. Column, mean; bar, SD. EMT, epithelial-mesenchymal transition; qPCR, quantitative polymerase chain reaction; $\mathrm{SD}$, standard deviation.

of cells in the $\mathrm{CoCl}_{2}$ group was double that of the control group. Cell migration was inhibited by curcumin. In addition, the $\mathrm{CoCl}_{2}$-enhanced migration of $\mathrm{HepG} 2$ cells was reduced by $\sim 40 \%$ with curcumin treatment. The migration distance 
of cells in the $\mathrm{CoCl}_{2}$ plus curcumin group decreased by $30 \%$ compared with that observed in the control group.

Invasiveness was determined by using Matrigel-coated transwell chambers. As shown in Fig. 3C and D, without curcumin intervention, $\mathrm{CoCl}_{2}$ treatment markedly increased the invasiveness of HepG2 cells in comparison with control cells.

As in the wound-healing assay, curcumin significantly inhibited cell invasion. The average number of cells that invaded the lower chamber in the curcumin-treated group was $50 \%$ lower than that of the control group. In addition, the enhanced cell invasion observed in the $\mathrm{CoCl}_{2}$ group was also inhibited by curcumin. The number of invasive cells in the $\mathrm{CoCl}_{2}$ plus curcumin group decreased by $\sim 60 \%$ compared with that in the $\mathrm{CoCl}_{2}$ group. These results indicate that curcumin inhibits migration and invasion of HCC cells under hypoxic conditions.

Effects of curcumin on the expression of EMT-related markers induced by HIF-1 $\alpha$ in HepG2 cells. Enhanced cell migration and invasiveness is often linked with EMT. As hypoxia has been shown to induce tumor cell EMT, this study aimed to determine whether curcumin had an effect on EMT markers as measured by qPCR and western blotting. The results showed that in response to $\mathrm{CoCl}_{2}$, HepG2 cells had decreased mRNA expression of the epithelial marker, E-cadherin. However, mRNA expression of the mesenchymal markers, vimentin and snail, increased significantly compared with that in the control cells. Treatment with curcumin markedly diminished the $\mathrm{CoCl}_{2}$-induced downregulation of E-cadherin, and upregulation of vimentin and snail mRNA levels (Fig. 4A). Measurement of protein levels showed similar results (Fig. 4B). These results demonstrated that curcumin suppressed EMT associated with HIF-1 $\alpha$ accumulation in HepG2 HCC cells.

\section{Discussion}

HCC is the one of the most common types of malignant disorder, which runs a rapidly progressive clinical course. It is rarely amenable to resection and does not generally respond well to non-surgical treatments, resulting in a poor prognosis (32). The majority of solid tumors, including HCC have been shown to have a hypoxic tumor microenvironment (33). Although hypervascularity and angiogenesis are important features of HCC, due to the increased demand for blood and oxygen supply as a consequence of rapid tumor growth, delivery of oxygen to the tumor is often insufficient.

Recently, evidence from a number of studies has suggested that hypoxic signaling is a central modulator of cellular physiology in cancer cells (34-36). Hypoxia is associated with a poor prognosis in several types of malignancy. Hypoxia-mediated target gene expression has been shown to stimulate proliferation (37), angiogenesis (38), metastasis (39), chemoresistance (40) and radio-resistance (41) of tumor cells. Suppression of tumor cell differentiation (42) and apoptosis (43) has been shown to lead to tumor progression in several types of cancers. Thus, therapeutic strategies aimed at improving the hypoxic intratumor microenvironment, or blocking the signaling pathways activated by hypoxia may be useful in the treatment of solid tumors, including HCC.

It has been well established that HIF-1 $\alpha$ is an important transcription factor that is specifically activated during hypoxia.
In response to intratumor hypoxia, HIF-1 $\alpha$ is stabilized and translocates to the nucleus where it forms a transcriptionally active complex, HIF-1, by coupling to HIF-1 $\beta$ (also termed ARNT) (44). HIF-1 modulates the expression of a number of target genes, the products of which control pathways involved in angiogenesis, cell survival and metastasis (45).

The current study shows that HIF-1 $\alpha$ accumulation in HepG2 cells is associated with enhanced migration and invasiveness. In addition, the alteration in levels of EMT-related molecules suggests that cells underwent EMT programming in the hypoxia model induced by $\mathrm{CoCl}_{2}$. This is in agreement with recent studies showing that hypoxia-mediated HIF-1 $\alpha$ accumulation leads to $\beta$-catenin overexpression in $\mathrm{HCC}$ cells, and is accompanied by enhanced invasiveness in vitro and metastasis in vivo (46). Considering the central role of HIF-1 $\alpha$ in hypoxia and the crucial role of HIF-1 $\alpha$ in cancer progression, chemotherapeutic agents that target HIF- $1 \alpha$ may be attractive modalities to prevent tumor progression.

Research over the last few decades has indicated that curcumin is a potent anti-inflammatory agent with strong therapeutic potential against a variety of types of cancer (22). Extensive studies have demonstrated that curcumin has the ability to suppress transformation, proliferation and metastasis of tumors by regulation of certain molecules involved in cancer progression $(16,24,25)$. The current study found that curcumin alone exhibited antitumor effects under normoxic conditions. In addition, the results indicated that curcumin may also inhibit HCC cell growth, migration and invasion under hypoxic conditions induced by $\mathrm{CoCl}_{2}$. A recent study has shown that curcumin suppresses proliferation and induces apoptosis of human HCC cells in a concentration-dependent manner by inhibiting the Wnt signaling pathway (47). In the current study, the antitumor effect of curcumin was found to be partially mediated by inhibiting HIF-1 $\alpha$ stabilization in HepG2 cells, without affecting HIF-1 $\alpha$ transcription. These results suggest potential for the treatment of HCC by altering the upregulation of HIF-1 $\alpha$ observed in HCC.

In conclusion, the current study indicated that curcumin inhibits hypoxia-induced HIF-1 $\alpha$ accumulation in HepG2 cells in a hypoxia model induced by $\mathrm{CoCl}_{2}$. Moreover, curcumin suppresses proliferation, migration, invasion and EMT of HepG2 cells in this environment. These results suggest that curcumin is a potential anticancer agent for the treatment of HCC.

\section{Acknowledgements}

The authors would like to thank Medjaden Bioscience Limited for assisting in the preparation of this manuscript. This study was financially supported by grants from the National Natural Science Foundation of China (no. 81201824), the Fundamental Research Funds for the Central Universities in Xi'an Jiaotong University (no. 2013jdhz33) and the Scientific Research Program Funded by Shaanxi Provincial Education Department (no. 11JK0704).

\section{References}

1. Jelic S and Sotiropoulos GC; ESMO Guidelines Working Group: Hepatocellular carcinoma: ESMO Clinical Practice Guidelines for diagnosis, treatment and follow-up. Ann Oncol 21: v59-v64, 2010 . 
2. Altekruse SF, McGlynn KA and Reichman ME: Hepatocellular carcinoma incidence, mortality and survival trends in the United States from 1975 to 2005. J Clin Oncol 27: 1485-1491, 2009.

3. El-Serag HB: Hepatocellular carcinoma. N Engl J Med 365: 1118-1127, 2011

4. Thiery JP, Acloque $\mathrm{H}$, Huang $\mathrm{RY}$ and Nieto MA: Epithelial-mesenchymal transitions in development and disease. Cell 139: 871-890, 2009.

5. Brabletz T, Jung A, Spaderna S, et al: Opinion: migrating cancer stem cells - an integrated concept of malignant tumour progression. Nat Rev Cancer 5: 744-749, 2005.

6. Kalluri R and Weinberg RA: The basics of epithelial-mesenchymal transition. J Clin Invest 119: 1420-1428, 2009.

7. Peinado H, Ballestar E, Esteller M and Cano A: Snail mediates E-cadherin repression by the recruitment of the Sin3A/histone deacetylase 1 (HDAC1)/HDAC2 complex. Mol Cell Biol 24: 306-319, 2004

8. Jou J and Diehl AM: Epithelial-mesenchymal transitions and hepatocarcinogenesis. J Clin Invest 120: 1031-1034, 2010.

9. Li X, Li P, Chang Y, et al: The SDF-1/CXCR4 axis induces epithelial-mesenchymal transition in hepatocellular carcinoma. Mol Cell Biochem 392: 77-84, 2014.

10. Vaupel P and Mayer A: Hypoxia in cancer: significance and impact on clinical outcome. Cancer Metastasis Rev 26: 225-239, 2007.

11. Lu X and Kang Y: Hypoxia and hypoxia-inducible factors: master regulators of metastasis. Clin Cancer Res 16: 5928-5935, 2010.

12. Dong ZZ, Yao M, Wang L, et al: Hypoxia-inducible factor-1alpha: molecular-targeted therapy for hepatocellular carcinoma. Mini Rev Med Chem 13: 1295-1304, 2013.

13. Chan DA, Sutphin PD, Yen SE and Giaccia AJ: Coordinate regulation of the oxygen-dependent degradation domains of hypoxia-inducible factor 1 alpha. Mol Cell Biol 25: 6415-6426, 2005.

14. Nyberg P, Salo T and Kalluri R: Tumor microenvironment and angiogenesis. Front Biosci 13: 6537-6553, 2008.

15. Zhao JH, Luo Y, Jiang YG, et al: Knockdown of $\beta$-Catenin through shRNA cause a reversal of EMT and metastatic phenotypes induced by HIF-1 $\alpha$. Cancer Invest 29: 377-382, 2011.

16. Singh S and Khar A: Biological effects of curcumin and its role in cancer chemoprevention and therapy. Anticancer Agents Med Chem 6: 259-270, 2006

17. De R, Kundu P, Swarnakar S, et al: Antimicrobial activity of curcumin against Helicobacter pylori isolates from India and during infections in mice. Antimicrob Agents Chemother 53: 1592-1597, 2009.

18. Wang J, Du XX, Jiang H and Xie JX: Curcumin attenuates 6-hydroxydopamine-induced cytotoxicity by anti-oxidation and nuclear factor-kappa B modulation in MES23.5 cells. Biochem Pharmacol 78: 178-183, 2009.

19. Jurenka JS: Anti-inflammatory properties of curcumin, a major constituent of Curcuma longa: a review of preclinical and clinical research. Altern Med Rev 14: 141-153, 2009.

20. Kim DC, Ku SK and Bae JS: Anticoagulant activities of curcumin and its derivative. BMB Rep 45: 221-226, 2012.

21. Olszanecki R, Jawień J, Gajda M, et al: Effect of curcumin on atherosclerosis in apoE/LDLR-double knockout mice. J Physiol Pharmacol 56: 627-635, 2005.

22. Shishodia S, Chaturvedi MM and Aggarwal BB: Role of curcumin in cancer therapy. Curr Probl Cancer 31: 243-305, 2007.

23. Jobin C, Bradham CA, Russo MP, et al: Curcumin blocks cytokine-mediated NF-kappa B activation and proinflammatory gene expression by inhibiting inhibitory factor I-kappa B kinase activity. J Immunol 163: 3474-3483, 1999.

24. Prakobwong S, Gupta SC, Kim JH, et al: Curcumin suppresses proliferation and induces apoptosis in human biliary cancer cells through modulation of multiple cell signaling pathways. Carcinogenesis 32: 1372-1380, 2011.

25. Yang CL, Liu YY, Ma YG, et al: Curcumin blocks small cell lung cancer cells migration, invasion, angiogenesis, cell cycle and neoplasia through Janus kinase-STAT3 signalling pathway. PLoS One 7: e37960, 2012
26. Guo M, Song LP, Jiang Y, et al: Hypoxia-mimetic agents desferrioxamine and cobalt chloride induce leukemic cell apoptosis through different hypoxia-inducible factor-1alpha independent mechanisms. Apoptosis 11: 67-77, 2006.

27. Li W, Ma J, Ma Q, et al: Resveratrol inhibits the epithelial-mesenchymal transition of pancreatic cancer cells via suppression of the PI-3K/Akt/NF- $\kappa B$ pathway. Curr Med Chem 20: 4185-4194, 2013.

28. Li X, Ma Q, Xu Q, et al: SDF-1/CXCR4 signaling induces pancreatic cancer cell invasion and epithelial-mesenchymal transition in vitro through non-canonical activation of Hedgehog pathway. Cancer Lett 322: 169-176, 2012.

29. Han L, Peng B, Ma Q, et al: Indometacin ameliorates high glucose-induced proliferation and invasion via modulation of e-cadherin in pancreatic cancer cells. Curr Med Chem 20: 4142-4152, 2013

30. Schmittgen TD and Livak KJ: Analyzing real-time PCR data by the comparative C(T) method. Nat Protoc 3: 1101-1108, 2008.

31. Ardyanto TD, Osaki M, Tokuyasu N, et al: $\mathrm{CoCl}_{2}$-induced HIF-1alpha expression correlates with proliferation and apoptosis in MKN-1 cells: a possible role for the PI3K/Akt pathway. Int J Oncol 29: 549-555, 2006.

32. Kew MC: Hepatocellular carcinoma in developing countries: Prevention, diagnosis and treatment. World J Hepatol 4: 99-104, 2012.

33. Wu XZ, Xie GR and Chen D: Hypoxia and hepatocellular carcinoma: The therapeutic target for hepatocellular carcinoma. J Gastroenterol Hepatol 22: 1178-1182, 2007.

34. Anastasiadis AG, Bemis DL, Stisser BC, et al: Tumor cell hypoxia and the hypoxia-response signaling system as a target for prostate cancer therapy. Curr Drug Targets 4: 191-196, 2003.

35. Kizaka-Kondoh S, Inoue M, Harada H and Hiraoka M: Tumor hypoxia: a target for selective cancer therapy. Cancer Sci 94: 1021-1028, 2003

36. Yasuda H: Solid tumor physiology and hypoxia-induced chemo/radio-resistance: novel strategy for cancer therapy: nitric oxide donor as a therapeutic enhancer. Nitric Oxide 19: 205-216, 2008.

37. Gordan JD, Bertout JA, Hu CJ, et al: HIF-2alpha promotes hypoxic cell proliferation by enhancing c-myc transcriptional activity. Cancer Cell 11: 335-347, 2007.

38. Liao D and Johnson RS: Hypoxia: a key regulator of angiogenesis in cancer. Cancer Metastasis Rev 26: 281-290, 2007.

39. Kalliomäki TM, McCallum G, Wells PG and Hill RP: Progression and metastasis in a transgenic mouse breast cancer model: effects of exposure to in vivo hypoxia. Cancer Lett 282: 98-108, 2009.

40. Selvendiran K, Bratasz A, Kuppusamy ML, et al: Hypoxia induces chemoresistance in ovarian cancer cells by activation of signal transducer and activator of transcription 3 . Int $J$ Cancer 125: 2198-2204, 2009.

41. Liu J, Zhang J, Wang X, et al: HIF-1 and NDRG2 contribute to hypoxia-induced radioresistance of cervical cancer Hela cells. Exp Cell Res 316: 1985-1993, 2010.

42. Kim Y, Lin Q, Glazer PM and Yun Z: Hypoxic tumor microenvironment and cancer cell differentiation. Curr Mol Med 9: 425-434, 2009.

43. Chiche J, Rouleau M, Gounon P, et al: Hypoxic enlarged mitochondria protect cancer cells from apoptotic stimuli. J Cell Physiol 222: 648-657, 2010.

44. Ke Q and Costa M: Hypoxia-inducible factor-1 (HIF-1). Mol Pharmacol 70: 1469-1480, 2006.

45. Powis G and Kirkpatrick L: Hypoxia inducible factor-1alpha as a cancer drug target. Mol Cancer Ther 3: 647-654, 2004.

46. Zhang Q, Bai X, Chen W, et al: Wnt $/ \beta$-catenin signaling enhances hypoxia-induced epithelial-mesenchymal transition in hepatocellular carcinoma via crosstalk with hif-1 $\alpha$ signaling. Carcinogenesis 34: 962-973, 2013.

47. Xu MX, Zhao L, Deng C, et al: Curcumin suppresses proliferation and induces apoptosis of human hepatocellular carcinoma cells via the wnt signaling pathway. Int J Oncol 43: 1951-1959, 2013. 